\title{
SYSTEMS OF MEASUREMENT: THEIR DEVELOPMENT AND USE IN MEDICINE
}

\author{
JoHN L. OULTON
}

\section{INTRODUCTION}

IT HAS BEEN ESTIMATED that $\$ 100$ million to $\$ 200$ million are lost each year to Canada by delay to convert to International System of Units. As more and more trading nations convert the costlier it will become for us to remain on the traditional system. Conversion in Canada received its official impetus from a Federal Government White Paper published in January 1970 which stated that the eventual conversion to the International System of Units (or S.I.) was an objective of Canadian policy. The White Paper envisaged voluntary change through consultation and cooperation, with the pace varied to suit individual sectors so that costs may be minimized and benefits optimized. It is anticipated, however, the conversion will be practically complete by 1980 .

Metrication and the world-wide use of the units of the Système Internationale is but a matter of time. All the major trading nations of the world, with the exception of the United States are using metric units or have declared their intention to do so in the near future.

Medicine is already utilizing metric units in many areas. Uniformity, however, is far from complete. In order to adapt to world scientific trends, medicine will certainly adopt metrication. The only question is "How fast?"

As we are now in a transition period in the world development of measurement systems, an historical summary with emphasis on the new system is worthy of review.

\section{History OF CUSTOMARY UNITS}

Earliest records show that the lengths of various parts of the human body were the original standards of measurement. From the point of the elbow to the tip of the middle finger was called a Cubit; from the end of the thumb to the tip of the little finger - a Span; the breadth of four fingers at the knuckles - a Palm; and the breadth of the first or middle fingers - a Digit.

Shorter distances were measured in steps or double steps. This method is still used for rough measuring as for a room or a baseball diamond.

Longer distances involved time. The ancient Jews would describe a journey as so many days from a certain place. An American Indian drawing depicts eight braves in two canoes on a journey lasting three days (three suns). (Figure 1.)

These measurements sufficed for an individual or for primitive peoples, but as

John L. Oulton, B.Sc., M.D., C.M., F.R.C.P.(C.), Department of Anaesthesia, University of British Columbia, Vancouver General Hospital, Vancouver, B.C., V5Z 1M9. 


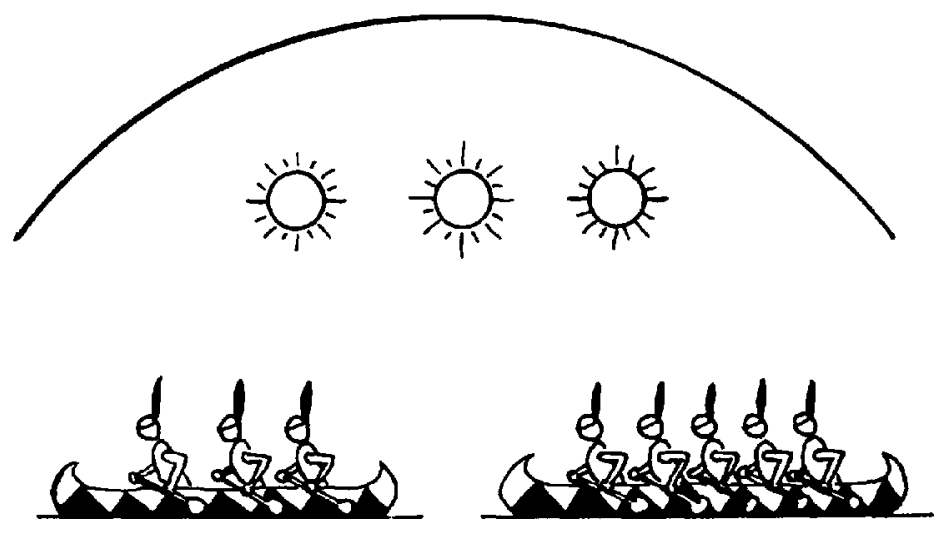

FiGURE 1.

civilizations and trade developed, measures were needed which would be the same for everyone. Governments tried to develop some form of standard measurements. The Cubit was the unit most frequently used. A 2-cubit measure was found in the Egyptian Karnak temple, which was built 3,000 years ago.

When the foot, which gets its name from the human foot, became a standard measure, no one is sure. However, it was an important measure in the time of the Greeks. The Romans adopted the foot from the Greeks and made it their standard measure of length for shorter distances. It actually was $11 \%$ of our inches though of 12 Roman inches.

The word Inch comes from the Latin Uncia, meaning a twelfth. Originally taken as the breadth of the thumb, it gradually replaced the Digit.

The Mile is from the Latin, Mille Passuum, a thousand paces. This referred to the Legionnaire or Roman pace of 5 feet each.

The Romans actually had standard measuring rods which were kept in a temple in Rome. With the fall of the Roman Empire these rods were lost with the result that measures began to vary in different parts of the old empire.

By the Middle Ages almost every town in Europe had its own standards. Even different trade guilds in a single city often had separate standards.

In England measures used by the Anglo-Saxons became the dominant postRoman system and the Normans made no significant change following the 1066 conquest. The Saxons, for their yard took the average distance around the waist of Saxon kings. A standard was made which was originally kept at Winchester, but later moved by the Normans to Westminster Abbey. In the Domesday Book, the Saxon yard was used as a unit of land measurement.

The customary or English system began about the twelfth century. Its development centred chiefly around the efforts of various monarchs and parliaments to reduce the chaos in measurements by setting specific standards for some of the most important units.

Henry I (1100-1135), started with the Yard. He decided that the standard Yard was to be the distance from the tip of his nose to the end of his thumb. In the six- 
teenth century, an Inch was described as the length of 3 grains of barley, laid end to end, round and dry, and taken from the centre of the ear. Elizabeth I (1558-1603) decreed that a Mile shall be five thousand, two hundred and eighty feet.

The story of the Pound begins with the Greeks and it comes from a Greek word meaning "the weight". The Romans adopted it and its use spread throughout the Roman Empire. A twelfth of a Pound was an Uncia, from which our word Ounce was derived.

Throughout the history of the Pound, the idea persisted that two different Pound weights should be used. A light Pound to weigh articles of high value and a heavy Pound to weigh articles of low value. The twelve ounce or Troy Pound and the sixteen ounce or Avoirdupois Pound both came to England from France.

An original Grain, for minute quantities, was the weight of a grain of wheat. A Troy Pound was the weight of 5760 grains and an Avoirdupois Pound was the weight of 7000 grains of wheat. The Troy and Apothecaries' weight for the Grain, Ounce and Pound, are the same.

The history of volume measurements is equally fascinating. Handfulls such as for corn or seeds was a primitive measurement. For liquids, eggshells, shells of sea animals, empty horns of animals and fruits such as gourds, were all used. After man learned to make vessels of pottery or of metal, measures of capacity became more standardized.

The Bushel and Gallon, our most important units of dry and liquid measure, have been in use since the thirteenth century. Gallon is believed to come from the French word meaning Bowl and Bushel from the French word Boissel.

An Imperial Gallon was determined to be the volume of ten Pounds Avoirdupois of pure water as weighed in air against brass weights, when the temperature of the air and water are $62^{\circ} \mathrm{F}$ and the barometric pressure is $30^{\prime \prime} \mathrm{Hg}$. The Gallon for convenience came to be frequently used in quarter gallon amounts. The word later was shortened to Quart.

The British Wine Gallon, standardized about 1700 by Queen Anne is approximately 20 per cent smaller. The U.S. Gallon is the British Wine Gallon.

Besides the common units of measurement, units associated with various types of endeavour became established. Some examples are the use of Picas and Points in printing, the Carat, the weight of a carob seed for diamond size and the Furlong for distance in horse racing.

The sheer number of units that got into everyday use in the English system was staggering, and although they may be considered picturesque, they have led to great confusion and numerous frauds.

The need for uniformity has long been recognized. However the successes of various monarchs and parliaments were, at best, limited.

The contrast in the ways in which the British and French went about solving this confusion in weights and measures is noteworthy. France simply discarded her old system and substituted a new one. England, on the other hand, improved its weights and measures situation through enforcement of stricter laws, and achieved widespread distribution through colonization and settlement.

Until the mid twentieth century, most of the English speaking nations of the world retained the customary English system of weights and measures. However, 
the French metric system was gradually spreading, mainly because of its appealing simplicity and logic.

\section{History OF THE METRic System}

The Metric System did not evolve from ancient practices; it was created to serve specific purposes. It has been called the first example of scientific rationalization by society.

Although Stevin (1585) first proposed a decimal system, the founding father of the metric system has been deemed to be Gabriel Mouton (1618-1694), the Vicar of St. Paul's Church in Lyon. In 1670 he proposed a comprehensive decimal system of weights and measures. He adopted the length of an arc of one minute of a great circle of the earth as his principal unit of length, which he called a Milliare. This system was never officially sponsored by pre-revolutionary French Governments. Meanwhile lack of coordination and standardization in weights and measures in France, as elsewhere, resulted in an almost unworkable situation.

Finally, in 1790, Talleyrand became the political sponsor of weights and measures in the Revolutionary National Assembly. Subsequently, French Academy Committees were appointed to study the introduction of a new system of weights and measures for France and, hopefully, for international use, based on the decimal system. Britain was invited to participate but declined because it felt the idea was impractical.

In 1791, recommendations were made. The unit of length would be one tenmillionth of the length of the meridian from the North Pole to the Equator through Paris. Later this was given the name Metre (Greek: metron, meaning a measure). The unit of mass was to be derived by cubing a part of this unit of length and filling it with water. This technique would also provide capacity measure. Hence standards of length, mass and capacity were all derived from a single measurement, infinitely reproducible because of natural origins, precisely interrelated and decimally based.

The Academy Committee further recommended that, as the terrain had already been surveyed, the arc of the meridian between Dunkirk in France, and Barcelona in Spain should be used to determine the unit of length. The team worked throughout the revolution, often under harassment, but eventually in November $179 \mathrm{~S}$ it had completed its work. By June 1799 the standards, a platinum metre and kilogram, were constructed.

Full adoption of the Metric System was slowed in 1812, when Napoleon decreed that the old units would be allowed to return. Confusion resulted until, in 1837, an act was passed which stated that after January 1st, 1840, only the decimal metric system was lawful for weights and measures.

In 1837, the Centimetre-Gramme-Second or C-G-S System was adopted for scientific purposes by the British Association for the Advancement of Sciences. These units are used still in medicine. For example, ventricular work is stated in g.cm./sec.

Following this, the metric system experienced a gradual steady growth as one country after another adopted it. At the beginning of the twentieth century, among 
the leading industrial nations of the world, only Britain with its empire and the U.S.A. had not accepted it.

The controlling body for the metric system is the Conférence Général des Poids et Mesures (CGPM) which was formed in 1875 at the signing by 17 countries of the Convention du Metre. The Comité International de Poids et Mesures (CIPM) is responsible for seeing that the CGPM decisions are carried out. The Bureau International des Poids et Mesures (BIPM) contains the standards laboratories at Sèvres, near Paris and is responsible to the CIPM. Some forty countries now send delegates to the Conférence Général and contribute to the upkeep of the Bureau.

About 1900, in Britain and the U.S.A., some practical measurements based on the metre, kilogram and second began to be used. This became known as the M-K-S System. In 1935, the International Electrotechnical Commission accepted that electro-magnetic units should be added to M.K.S. In 1950, this was finally adopted with the Ampere as the unit of electric current. Thus the M.K.S. now became the M.K.S.A. System.

To these units, in 1954, the CGPM added the kelvin as the unit of temperature and the candela as the unit of luminous intensity. Finally, in 1971 the mole was adopted as the unit of amount of substance, and became the seventh and last base unit of the Système Internationale d'Unites.

\section{The INTERNATIONAL SYSTEM OF UNITS (S.I.)}

Simplification is one of the major advantages of the S.I. System. The expansion of science and technology has been enormous, but it has tended to cause fragmentation, with each fragment or branch having its own terminology and units. Relevant results reported by a worker in one field may be difficult to interpret and appreciate by a worker in another. S.I., which has been described as a modernized metric system, has as its aim to do away with the present confusion and to facilitate communication between individuals, disciplines and nations.

In any measurement, we have a number plus a unit designation. With today's multiple terminology, although the numbers are from the same system, the units may be very different, even though we are measuring the same thing.

Units of concentration, of which there are over thirty, illustrate an example of difficult interpretation with which we are confronted daily.

Standardization of symbols is another advantage of S.I. Although the spelling of the names of units is altered depending on the language being used, the symbols for the units are the same internationally.

S.I. is comprehensive for it is based on seven dimensionally independent and two supplementary units. It is devised so that any one parameter will always be described in the same base unit. It is coherent because the units may be combined according to physical laws to obtain derived units.

In this way a logical interrelated system is constructed.

\section{Examples:}

Units:

length $(1)=$ metre 
TABLE I

\begin{tabular}{|c|c|c|c|}
\hline & Quantity & Unit & Symbol \\
\hline Base Units: & $\begin{array}{l}\text { Length } \\
\text { Mass } \\
\text { Time } \\
\text { Electric current } \\
\text { Thermodynamic temperature } \\
\text { Amount of substance } \\
\text { Luminous intensity }\end{array}$ & $\begin{array}{l}\text { metre } \\
\text { kilogram } \\
\text { second } \\
\text { ampere } \\
\text { Kelvin } \\
\text { mole } \\
\text { candela }\end{array}$ & $\begin{array}{l}\mathrm{m} \\
\mathrm{kg} \\
\mathrm{s} \\
\mathrm{A} \\
\mathrm{K} \\
\mathrm{mol} \\
\mathrm{cd}\end{array}$ \\
\hline $\begin{array}{l}\text { Supplementary } \\
\text { Units: }\end{array}$ & $\begin{array}{l}\text { Plane angle } \\
\text { Solid angle }\end{array}$ & $\begin{array}{l}\text { radian } \\
\text { steradian }\end{array}$ & $\begin{array}{l}\text { rad } \\
\text { st }\end{array}$ \\
\hline
\end{tabular}

area $\left(1^{2}\right)=$ square metre

volume $\left(1^{3}\right)=$ cubic metre

Derived units:

velocity $\left(\right.$ IS $\left.^{-1}\right)=$ metres per second

acceleration $\left(1 S^{-2}\right)=$ metres per second per second

Derived units with a special name:

force $=$ newton (kilogram metre per second per second $)$

pressure $=$ pascal (newton per square metre)

The adoption of S.I. is rational because the widely used M.K.S.A. System is absorbed and extended.

Each unit of S.I. has a name, an international symbol and an international definition. (Table I).

Decimal multiples and submultiples of the units are formed by means of prefixes. Greek prefixes indicate multiples and Latin prefixes indicate submultiples. (Table II).

The use of prefixes is governed by several rules, such as that only one prefix may be used at any one time. For example, $10^{-9}$ is nanometre, not milli micro metre. A symbol comprising a unit and prefix is regarded as a single symbol which may be raised to a positive or negative power, e.g. $\mathrm{mm}^{3}$. The choice of the multiple or submultiple is governed by convenience, the multiple chosen being the one which will lead to numerical values within a practical range. Generally speaking, the multiple chosen can usually result in numerical values between 0.1 and 1000 .

In addition, there are a few non-SI units which are of such practical importance that they will be retained. These include the litre, hour and minute.

The S.I. units are independently defined by a measurement standard that gives the exact value, and is reproducible in any adequately equipped laboratory.

\section{Definitions of S.I. Base Units}

\section{Metre}

The metre is the name of the S.I. unit of length. It is defined as the length equal to 1650763.73 wavelengths in vacuum of the orange-red line of the spectrum of the Krypton- 86 atom. 
TABLE II

\begin{tabular}{lcc}
\hline Prefix & Multiple Factor & Symbol \\
\hline tera & $10^{12}$ & $\mathrm{~T}$ \\
giga & $10^{9}$ & $\mathrm{G}$ \\
mega & $10^{6}$ & $\mathrm{M}$ \\
kilo & $10^{3}$ & $\mathrm{k}$ \\
hecto & $10^{2}$ & $\mathrm{~h}$ \\
deca & $10^{1}$ & da \\
deci & $10^{-1}$ & $\mathrm{~d}$ \\
milli & $10^{-2}$ & $\mathrm{~m}$ \\
& & etc. \\
\hline
\end{tabular}

The possible error is one part in one hundred million.

Since 1955, the invention of the laser has brought spectacular progress to interferometric procedures. The BIPM has been particularly interested in continuously operating helium-neon lasers. It can be predicted that the speed of light and lockstabilized lasers will play an important role in length measurements and will most likely be the basis of a new definition of the metre.

\section{Kilogram}

The kilogram is the standard for the S.I. unit of mass and is a cylinder of platinum-iridium alloy kept at the International Bureau of Weights and Measures at Sèvres near Paris. The kilogram is the only base unit still defined by an artifact.

\section{Second}

In 1964, the CIPM defined the second as the duration of 9192631770 cycles of the radiation associated with a specified transition of the cesium-133 atom. It is realized by tuning an oscillator to the resonance frequency of cesium- 133 atoms as they pass through a system of magnets and a resonant cavity into a detector.

The Canadian equipment has an absolute accuracy of one microsecond per year.

\section{Kelvin}

The metric S.I. unit of temperature is the kelvin (K). Each unit is 1/273.16 of the thermodynamic temperature of the triple point of water. This is a unique point at which ice, water and vapour co-exist in equilibrium at a pressure of 610.6 newtons per square metre. It is reproducible and used for calibration of thermometers.

Water freezes at $273.15 \mathrm{~K}$ and boils at $373.15 \mathrm{~K}$. The lowest possible temperature is zero $\mathrm{K}$ which equals absolute zero.

The degree kelvin is identical to the degree Celsius. Celsius (formerly called centigrade) denotes $0^{\circ}$ for the ice point and $100^{\circ}$ for the boiling point of water. The Celsius scale has gained general world usage because of the commonly used temperature ranges covered. To convert from Kelvin to Celsius, subtract 273.15.

\section{Ampere}

The S.I. unit of electrical current is the ampere (A). It is defined as the constant current which, if maintained in two straight parallel conductors of infinite length, 
of negligible circular cross-section, and placed one metre apart in a vacuum would produce between these conductors a force (due to their magnetic fields) equal to $2 \times 10^{-7}$ newton per metre of length.

\section{Candela}

The S.I. unit candela is the luminous intensity in the perpendicular direction from a cavity or black body of a surface area of $1 / 600,000$ square metre at the temperature of freezing platinum (2045K) under a pressure of 101325 newtons per square metre. This cavity or container, called the radiator should produce the luminous intensity of sixty candelas per square centimetre at the opening provided at the top of the radiator.

\section{Mole}

The mole is the S.I. unit of the amount of substance of a system. It is defined as containing as many elementary entities as there are atoms in 0.012 kilograms of carbon 12 . When the mole is used, the elementary entities must be specified and may be atoms, molecules, electrons, ions or other particles.

A mole of any substance contains $6.025 \times 10^{23}$ (Avogadro's number) entities so that it is a practical unit proportional to the number of molecules. It is also a quantity of a substance that has a weight in mass units numerically equal to its molecular weight (mass).

A gram molecular weight of a gas is measured in volume occupied by that weight under specific conditions, e.g. 22.4 litres at $0^{\circ} \mathrm{C}$ and $760 \mathrm{mmHg}$.

\section{S.I. IN MEDICINE}

Medicine, which receives input from many scientific disciplines, should benefit greatly from the simplification offered by measurements reported in S.I. units. However, the major fields of which measurements are used every day in Medicine, are physics, physiological measurements, clinical chemistry and drug dosages.

For the physician, the study of physics mainly refers to that section known as mechanics. Its practical application involves pressure regulators, gauges, ventilators, respiratory mechanics and haemodynamics.

It is important to differentiate clearly between mass and weight. Mass is essentially a quantity of matter. If a standard object (mass) has different forces applied to it, different accelerations will result. (Newton's 2nd Law of Motion). If a given force is applied to different objects (masses), different accelerations will result.

Therefore force $\propto$ mass $\times$ acceleration. It would take the same force to accelerate a given body in free space as it does to accelerate it along a horizontal frictionless surface of the earth, because its mass is the same in each place.

The weight of a body is the gravitational force exerted on it by the earth. If a mass is allowed to fall freely, its acceleration is that of the force of gravity denoted by " $g$." " $g$ " has been found experimentally to have the same value for all objects at the same place. But " $\mathrm{g}$ " varies with the distance of the object from the centre of the earth, until in space it becomes zero, yet the mass remains constant.

Thus in gravitational terms: 
TABLE III

\begin{tabular}{lcl}
\hline \hline Customary units & S.I. \\
\hline p.s.i. $\left(1 \mathrm{bf} /\right.$ in $\left.^{2}\right)$ & 6894.76 & $\mathrm{~Pa}$ \\
inch $\mathrm{H}_{2} \mathrm{O}$ & $6.89 \mathrm{kPa}$ \\
feet $\mathrm{H}_{2} \mathrm{O}$ & 249.2 & $\mathrm{~Pa}$ \\
$\mathrm{~mm} \mathrm{H}_{2} \mathrm{O}$ & 2990.4 & $\mathrm{~Pa}$ \\
$\mathrm{~cm} \mathrm{H}_{2} \mathrm{O}$ & 9.81 & $\mathrm{~Pa}$ \\
$\mathrm{~mm} \mathrm{Hg}$ & 98.1 & $\mathrm{~Pa}$ \\
inches Hg & 133.3 & $\mathrm{~Pa}$ \\
$\mathrm{~kg} / \mathrm{cm}^{2}\left(\mathrm{kp} / \mathrm{cm}^{2}\right)$ & 3385.82 & $\mathrm{~Pa}$ \\
& $3.386 \mathrm{kPa}$ \\
Torr & 98043.48 & $\mathrm{~Pa}$ \\
bar & 98.04 & $\mathrm{kPa}$ \\
atmosphere & 133.3 & $\mathrm{~Pa}$ \\
\hline
\end{tabular}

$F=W=m g$. This weight, or force of gravity will vary according to the location of the mass, and over the earth's surface will alter up to 0.5 per cent. This is not accurate enough for scientific work. We therefore have two systems of force, the absolute and the gravitational. The S.I. units belong to the absolute system.

The fundamental units of mechanics are mass $(m)$, length $(1)$ and time $(t)$. The S.I. unit of mass is the kilogram, the unit of length the metre, and the unit of time the second.

As previously defined $\mathrm{F} \propto \mathrm{ma}$, or $\mathrm{F}=\mathrm{kma} . \mathrm{k}$ is a simple number, and if the values of the equation are set so that $\mathrm{k}$ may equal 1 , then, $\mathrm{F}=\mathrm{ma}=\mathrm{mlt}^{-2}$.

The S.I. unit of force, the newton, is that force which, when applied to a mass of one kilogram, will accelerate it one metre per second per second.

Therefore, $\mathrm{N}=\mathrm{kg} \mathrm{ms}^{-2}$

Pressure is defined as force per unit area.

$$
\mathrm{P}=\mathrm{F} / 1^{2}=\mathrm{ma} / 1^{2}=\mathrm{mlt}-2 / 1^{2}=\mathrm{m}^{-1} \mathrm{t}^{-2}
$$

Pressure then has units of mass, length and time. In S.I.

$$
\mathrm{P}=\mathrm{F} / 1^{2}=\mathrm{Nm}^{-2}=\mathrm{kg} \mathrm{m}^{-1} \mathrm{~s}^{-2} \text {. }
$$

$\mathrm{Nm}^{-2}$ has been given the special name pascal and its symbol is $P a$.

In the customary system, we have a confusing array of units of pressure. The unit used depends on what is being measured. Table III lists pressures utilized in Medicine and their equivalents in $\mathrm{Nm}^{-2}$, i.e. the pascal.

A standard atmosphere equals $101.325 \mathrm{kPa}$. Therefore $1 \mathrm{kPa}$ equals approximately $1 \%$ of an atmosphere. This convenient relationship allows us to translate percentages of a gas at atmospheric pressure into $\mathrm{kPa}$ utilizing the same number. For example, $5 \% \mathrm{CO}_{2}$ exerts approximately $5 \mathrm{kPa}$ and $\mathrm{P}_{\mathrm{O}_{2}}$ at sea level exerts approximately $21 \mathrm{kPa}$.

Other examples of commonly used pressure are: blood pressure: $120 / 80 \mathrm{mmHg}$ $=16 / 11 \mathrm{kPa}$; oxygen cylinder: 2000 p.s.i. $=13.79 \mathrm{MPa}$; inflation pressure: $20 \mathrm{~cm}$ $\mathrm{H}_{2} \mathrm{O}=19.6 \mathrm{hPa}$.

Thus all pressures in all fields will be expressed in terms of a single unit, the pascal. 
Work is defined as force applied through a distance. A joule ( $J$ ) is the S.I. unit of work. Energy, which may be considered as stored ability to do work, has the same unit. A joule represents the amount of work done when a newton is applied through 1 metre.

$$
\begin{aligned}
\text { Symbolically, } \mathrm{J} & =\mathrm{Nm} \\
& =\mathrm{kg} \mathrm{ms}^{-2} \mathrm{~m} \\
& =\mathrm{kg} \mathrm{m}^{2} \mathrm{~s}^{-2}
\end{aligned}
$$

In respiratory mechanics, work is done as a pressure gradient causes gas to move. One joule of work is performed when a litre is moved in response to a pressure gradient of 1 kilopascal.

Thus, $11 \times 1 \mathrm{kPa}=10^{-3} \mathrm{~m}^{3} \times 10^{3} \mathrm{Nm}^{-2}=1 \mathrm{Nm}=1 \mathrm{~J}$.

Compliance, now expressed in $1 / \mathrm{cm} \mathrm{H}_{2} \mathrm{O}$ would probably be expressed in $1 / \mathrm{kPa}$.

In 1971, in response to requests from the International Union of Pure and Applied Physics, the International Organization of Pure and Applied Chemistry, and the International Organization of Standardization, the General Conference of Weights and Measures introduced a unit for the amount of substance. This unit is the mole.

In clinical chemistry, implementation of S.I. will mean a change from mass units $(\mathrm{mg} / 100 \mathrm{ml})$ to molar units (moles/litre).

The molecular weight of a substance (in grams) is one mole, therefore the mass of a substance divided by its molecular weight gives the number of moles. A mole contains $6.025 \times 10^{23}$ entities; the value of this unit therefore is its indication of numbers of particles of any substance.

This change in concept from mass to molar concentration may have serious implications initially. However, its use will ultimately aid in the better understanding of laboratory data.

Molar units are a more meaningful presentation because physiological relations become more obvious when constituents are measured on the basis of their relative number rather than their molecular weight.

$\begin{array}{lcr}\text { Example } & \text { Now } & \text { S.I. } \\ \text { Urea } & 73 \mathrm{mg} / 100 \mathrm{ml} & 12.16 \mathrm{~m} \mathrm{~mol} / 1 \\ \text { Cholesterol } & 250 \mathrm{mg} / 100 \mathrm{ml} & 6.46 \mathrm{~m} \mathrm{~mol} / 1\end{array}$

On a weight basis, it would appear that there is three and a half times as much cholesterol as urea, but on a molecular level, there are twice as many molecules of urea as of cholesterol.

If the tetramer $(\mathrm{Hb})_{4}$ of haemoglobin is considered:

$\mathrm{Hb}$ contains $\mathrm{Fe}$ and $\mathrm{O}_{2}$

$1 \mathrm{gm}$ contains $5 \mathrm{mg}$ and $1.4 \mathrm{ml}$

1 molecule contains 4 molecules and 4 molecules.

At the molecular level the chemical interaction is visualized with greater ease.

Units of concentration at present differ because various baselines are taken depending on the size of the sample. Results are usually expressed in grams or milligrams, but this often becomes confusing because the denominator varies. The 
milliequivalent was introduced for electrolytes. Measurement of calcium and magnesium in $\mathrm{mg} / 100 \mathrm{ml}$ obscures their quantitative relationship to other cations which normally are expressed in milliequivalents per litre.

Only the concentration of the monovalent electrolytes usually measured in milliequivalents per litre will be reported in the S.I. system with numerical values which will appear meaningful because their concentrations in millimoles per litre and milliequivalents per litre are the same. All others will appear to bear no relation between readings in molar terms and mass concentrations.

$\begin{array}{lcc} & \text { Familiar } & \text { New } \\ \text { Sodium } & 130 \mathrm{mEq} / 1 & 130 \mathrm{~m} \mathrm{~mol} / 1 \\ \text { Potassium } & 5 \mathrm{mEq} / 1 & 5 \mathrm{~m} \mathrm{~mol} / 1 \\ \text { Calcium } & 10 \mathrm{mg} / 100 \mathrm{ml} & 2.5 \mathrm{~m} \mathrm{~mol} / 1\end{array}$

Millimoles per litre and milligrams per $100 \mathrm{ml}$ are related by the formula.

$$
\frac{\text { Milligrams per } 100 \mathrm{ml} \times 10}{\text { molecular weight }}=\text { millimoles per litre }
$$

Examples

Serum calcium: $10 \mathrm{mg} / 100 \mathrm{ml}$. Mol.wt. 40

$10 \times 10 / 40=2.5 \mathrm{~m} \mathrm{~mol} / 1$

Blood glucose: value of $90 \mathrm{mg} / 100 \mathrm{ml}$. Mol.wt. 180

$90 \times 10 / 180=5.0 \mathrm{~m} \mathrm{~mol} / 1$

Drug dosages expressed in moles rather than mass would be entirely logical. Morphine sulphate $10 \mathrm{mg}$ contains approximately $8 \mathrm{mg}$ morphine. However, 1 mole of morphine or morphine sulphate contains the same quantity of morphine. The commercial preparation of norepinephrine contains $2 \mathrm{mg} / \mathrm{ml}$ of the bitartrate salt or $1 \mathrm{mg} / \mathrm{ml}$ of norepinephrine base. Confusion over orders for norepinephrine has recently led to new labelling regulations. Using molar dosages, this confusion would disappear.

In the barbiturate group, the same mass does not indicate equal potency. Dosages at the molecular level, however, would give an indication of molecular potency and thus provide a logical measure for comparison.

\section{INTRODUCTION OF S.I.}

Professional organizations throughout the world recognize the ultimate advantages of uniformity. Not for the sake of uniformity, but for comprehension and communication.

About 40 per cent to 50 per cent of British hospitals now have changed and it was anticipated that practically all would have adopted S.I. by the end of 1975 . The main problem would appear to be that the change-over, when made, be done in an organized fashion so that one or more branches did not get out of step.

Medicine, already a user of some metric units, is well situated to adopt S.I. With its gradual introduction in journals, textbooks and medical schools, complete metrication is undoubtedly a fact of the future. 


\section{SUMMARY}

A brief historical review of customary measurements, the resultant chaos and the desirability for a simplified unified measurement system is discussed.

The basic units of the International System of Units are described and defined, along with their application in Medicine.

\section{ACKNOWLEDGMENTS}

The author wishes to thank Dr. Gordon C. Page, University of British Columbia, for his advice and Miss Fay Son-Hing for her valuable secretarial assistance in the preparation of this manuscript.

\section{REFERENCES AND SUGGESTED ADDITIONAL READING}

Canadian Standards Association. Special paper on the international system of units. June (1973). The U.S. Department of Commerce, National Bureau of Standards. Special publication, 420.

The 1975 World Encyclopedia Supplement. Field Enterprises Educational Corporation. Chicago. BLAck, G.J. Canada goes metric. Doubleday. Toronto (1974).

Metric conversion kit for hospitals. Canadian Hospital Association (1975).

HrLl, D.W. The application of S.I. units to anaesthesia. Br. J. Anaesth. $41: 1053$ (1969).

Personal communication. National Research Council. Time and Frequency Section.

Padmore, G.R.A. \& Nunn, J.F. S.I. units in relation to anaesthesia. Br. J. Anaesthesia. 46: 236 (1974).

Younc, D.S. Standardized reporting of laboratory data. N.E.J.M. 290: 368 (1974). 